\title{
Effect of Water Deficit Stress on Yield Performances in Wet Seeded Rice
}

\author{
S Parveen ${ }^{1 *}$, E Humphreys² and M Ahmed ${ }^{3}$
}

\begin{abstract}
Worldwide fresh water scarcity and labour unavailability in agriculture are driving researchers and farmers to find management strategies that will increase water productivity and reduce labour requirement. Wet seeding instead of transplanting rice greatly reduces the labour requirement for crop establishment, while use of alternate wetting and drying (AWD) instead of continuous flooding reduces irrigation input. However, the safe threshold for irrigating wet seeded rice (WSR) at different crop stages has not been investigated. Therefore, experiment was conducted to determine the effects of different degrees of water stress during different crop growth stages on yield performance of WSR. This was done in greenhouse experiment in the 2011 wet season 2011 at the International Rice Research Institute, Los Baños, Philippines. In the experiment, water stresses were applied by withholding irrigation until soil water tension increased to 10,20 or $40 \mathrm{kPa}$ (kilo pascal) at $10 \mathrm{~cm}$ below the soil surface. Soil water tension was measured using $30 \mathrm{~cm}$ long guage tensiometer installed with the center of the ceramic cup. The stresses were applied during three crop stages: 3-leaf (3L) to panicle initiation (PI), PI to flowering (FL), and FL to physiological maturity (PM). The experiment also included a continuously flooded (CF) treatment. The number of drying events ranged from 8-12 during 3L-PI, 6-10 during PI-FL and 6-10 during FL-PM. There was a consistent trend for a decline in the number of irrigations and irrigation input with increasing irrigation threshold, and thresholds of 20 and $40 \mathrm{kPa}$ resulted in significantly lower input than with CF. There were consistent trends for lower grain yield as the level of water deficit stress increased, and imposition of stresses of 20 and $40 \mathrm{kPa}$ at any or all three stages significantly reduced grain yield compared with CF. There was a trend for the reduction in grain yield to be greater when the stresses were imposed at all three stages compared with a single stage, but the differences were not significant. There was a consistent trend for irrigation water productivity (WPi) to decrease as the irrigation threshold increased, with significantly lower values for a $40 \mathrm{kPa}$ threshold at any stage, in comparison with CF. This was because the decline in water input to the pots was less than the decline in yield as the threshold increased. The results suggest that the optimum threshold for irrigation of WSR is $10 \mathrm{kPa}$ during the vegetative and grain filling stages, and that the soil should be kept at close to saturation during PI-FL.
\end{abstract}

Key words: Water productivity, soil water tension, wet season, physiological maturity

\section{INTRODUCTION}

In most of Asia, irrigated rice is manually transplanted into puddled soil, and the fields are continuously flooded for most of the season until shortly before harvest. However, peak period labour scarcity has greatly increased the cost of transplanting and often results in delayed crop establishment. Therefore, there is a growing interest in direct seeded rice because of its low labour requirement. There are three basic forms of direct seeding - water seeding, dry seeding and wet seeding (Kumar and
Ladha, 2011). Wet seeding involves puddling of the soil prior to sowing pre-germinated seed by manual broadcasting or line seeding (using a manually pulled drum seeder, Rashid et al., 2009) onto the saturated soil surface. Like irrigated, puddled transplanted rice (PTR), wet seeded rice (WSR) requires large amounts of water for puddling and to keep the field continuously flooded after establishment. Furthermore, WSR may require more irrigation water than PTR as it takes for longer time in the main field (Cabangon et al., 2002). Assuming the increasing scarcity of water for agriculture

\footnotetext{
${ }^{1}$ Bangladesh Rice Research Institute, Gazipur, Bangladesh. ${ }^{2}$ International Rice Research Institute, Los Banos, Philippines. ${ }^{3}$ Bangladesh Agricultural University, Mymensingh, Bangladesh. *Corresponding author's E-mail : parveenbrri98@yahoo.com
} 
together with the need to increase production to feed growing populations, there has been a lot of effort to identify methods for reducing irrigation water input to rice while maintaining yield (Guerra et al., 1998; Bouman et al., 2005; Humphreys et al., 2010). However, lowland rice varieties are highly sensitive to soil drying, with yields generally declining once the soil starts to dry below saturation. In their review, Bouman and Tuong (2001) found yield reductions of $0-12 \%$ when the soil was kept at saturation instead of flooded, and of $10-40 \%$ when soil tension in the root zone was allowed to increase to 10 to $30 \mathrm{kPa}$. However, safe alternate wetting and drying (AWD) water management has proven to be a successful and practical means of reducing irrigation input to PTR by $10-40 \%$ while maintaining yield (Bouman and Tuong, 2001). With safe AWD, the field is flooded to a shallow depth $(\sim 5 \mathrm{~cm})$ for about two weeks after transplanting, after which irrigation is managed to ensure that the soil water tension at $15 \mathrm{~cm}$ depth does not exceed about $10 \mathrm{kPa}$. The same threshold is applied throughout the duration of the crop, except during the heading/flowering period when keeping the soil saturated/ flooded is recommended (Bouman et al., 2005). While a threshold of $10 \mathrm{kPa}$ is safe in a range of soil types, there are situations where higher thresholds of 20 to $60 \mathrm{kPa}$ throughout the season did not cause a loss of yield (eg Kukal et al., 2005; Bueno et al., 2010; Sudhir-Yadav et al., 2011). The safe threshold depends on many factors including genotype, soil type, frequency of drying events, evaporative demand, and growth stage.

The effect of water deficit stress at different crop stages has been the subject of many drought studies, primarily targeted at rainfed, lowland rice. These studies typically involved imposing high levels of water deficit stress by withholding irrigation for many days until the crop was stressed to the degree of complete leaf rolling (soil tension in excess of $500 \mathrm{kPa}$, Wopereis et al., 1996), or until there was significant leaf death. This was then followed by well-watered conditions to maturity. These studies showed that periods of drought delayed phenological development, but much more so (by up to about three weeks) when the stress was applied during the vegetative phase (Woopereis et al., 1996; Castillo et al., 2006; Davatgar et al., 2009). In these studies, applying stress during the reproductive stage (panicle initiation, booting, flowering) was more detrimental to grain yield than applying stress during the early vegetative stage, while applying the stress during mid tillering was also detrimental. However, while it is generally agreed that the period during anthesis is especially sensitive to drought stress, the review of Bouman and Tuong (2001) found no systematic trend for greater yield reduction when drought was imposed in certain development stages compared with other developmental stages. The results of De Datta et al, (1973) (in Bouman et al., 2001) showed that different cultivars had different responses to drought stress timing and intensity. With soil drying to $50 \mathrm{kPa}$, some cultivars showed more yield reduction with drought imposed during the vegetative stage than in the reproductive stage, some showed the reverse and some showed higher yields with drought in the vegetative stage than in the well-watered control.

In irrigated rice culture, the usual goal of water saving irrigation management is to avoid stressing the crop to the degree that yield is reduced, while minimizing irrigation input. The degree to which the soil can be allowed to dry during different crop phases without affecting yield, and whether there is a cumulative effect of low levels of water deficit stress across all crop stages are not well understood. Furthermore, in contrast with the situation for transplanted rice, reports on the response of WSR to soil drying below saturation are lacking. Therefore, the objectives of the study were: to understand the effect of threshold level on number and amount of irrigation and effect of water stress on yield and yield components.

\section{MATERIALS AND METHODS}

The research was carried out in the greenhouse at the International Rice Research Institute 
(IRRI), Los Baños, Philippines $\left(14^{\circ} 11^{\prime} \mathrm{N}\right.$, $\left.121^{\circ} 15^{\prime} \mathrm{E}\right)$, from July to November 2011. Rice was grown on a silty clay loam soil (28\% sand, $34 \%$ silt, 39\% clay) in $20 \mathrm{~cm}$ diameter, $25 \mathrm{~cm}$ high polyvinyl chloride pots. Bulk soil was obtained from the IRRI experimental station, homogenized well with water and added to the pots to a depth of $20 \mathrm{~cm}$. The soil was re-puddled using an electrical stirrer before wet seeding. The soil was slightly acidic, with medium levels of organic $\mathrm{C}$, available $\mathrm{P}$, exchangeable $\mathrm{Ca}$ and $\mathrm{K}$, and total $\mathrm{N}$ (Table 1 ).

The experiment was designed to evaluate the effects of different levels of water stress at different growth stages. There were three levels of water stress $(10,20$ and $40 \mathrm{kPa}$ soil water tension) applied at one of three growth stages: 3 leaf (3L) to panicle initiation (PI), PI to flowering (FL), and FL to physiological maturity (PM) (Table 2). In addition there was a control treatment, which was continuously flooded (CF), and three treatments, which had stresses of 10, 20 or $40 \mathrm{kPa}$ during all the three stages. Thus, there were 13 water management treatments in a randomized complete block design.

Implementation of $\mathrm{CF}$ involved topping the pots up daily to a pond water depth of 2 to $3 \mathrm{~cm}$. For the stress treatments, irrigation was applied whenever soil water tension increased to the threshold value $(10,20$ or $40 \mathrm{kPa})$, with water added in two doses, topping up to a depth of $2 \mathrm{~cm}$ each time, to ensure that the soil was fully saturated to depth. Soil tension was measured using 30-cm long tensiometers installed in 4 replicate pots of each treatment. The tensiometers were installed $4 \mathrm{~cm}$ to the side of the centre of the plant rows, and the middle of the ceramic cup was $10 \mathrm{~cm}$ below the soil surface. All pots of a given treatment were irrigated when the average of the four monitored pots reached the threshold value. All pots were kept continuously flooded at all
Table 2. Water management treatments.

\begin{tabular}{lccc}
\hline \multirow{2}{*}{ Treatment } & \multicolumn{3}{c}{$\begin{array}{c}\text { Irrigation threshold during each crop } \\
\text { stage }^{\mathrm{a}}(\mathrm{kPa})\end{array}$} \\
\cline { 2 - 4 } CF-CF-CF & 3L to PI & PI to FL & FL to PM \\
\hline 10-CF-CF & 10 & CF & CF \\
20-CF-CF & 20 & CF & CF \\
40-CF-CF & 40 & CF & CF \\
CF-10-CF & CF & 10 & CF \\
CF-20-CF & CF & 20 & CF \\
CF-40-CF & CF & 40 & CF \\
CF-CF-10 & CF & CF & CF \\
CF-CF-20 & CF & CF & 10 \\
CF-CF-40 & CF & CF & 40 \\
$10-10-10$ & 10 & 10 & 10 \\
$20-20-20$ & 20 & 20 & 20 \\
$40-40-40$ & 40 & 40 & 40 \\
\hline
\end{tabular}

a3L=3 leaf stage, $\mathrm{PI}=$ panicle initiation, $\mathrm{FL}=$ flowering, $\mathrm{PM}=$ physiological maturity, $\mathrm{CF}=$ continuously flooded.

stages other than during the stage when the 10, 20 or $40 \mathrm{kPa}$ stresses were being applied.

After the final puddling, the soil was allowed to settle for $1 \mathrm{~d}$. A solution of $27 \mathrm{ml}$ of fertilizer containing muriate of potash, diammonium phosphate and zinc sulphate was poured onto the soil surface $24 \mathrm{~h}$ before seeding, giving a basal fertilizer application rate of 40 $\mathrm{kg} \mathrm{K}_{2} \mathrm{O} \mathrm{ha}^{-1}, 41 \mathrm{~kg} \mathrm{P}_{2} \mathrm{O}_{5} \mathrm{ha}^{-1}, 30 \mathrm{~kg} \mathrm{~N}^{-1}$ and 5 $\mathrm{kg} \mathrm{Zn} \mathrm{ha-1.} \mathrm{Urea} \mathrm{was} \mathrm{top-dressed} \mathrm{at} \mathrm{maximum}$ tillering, PI and heading at 50, 50 and $30 \mathrm{~kg} \mathrm{~N}$ $\mathrm{ha}^{-1}$, respectively, and muriate of potash $(40 \mathrm{~kg}$ $\mathrm{ha}^{-1}$ ) was also applied at PI. The top dressing was done immediately prior to irrigation.

The rice variety NSIC Rc222 was pregerminated by soaking the seeds for $24 \mathrm{~h}$, draining, then incubating for $24 \mathrm{~h}$ prior to sowing. NSICRc222 was selected for its high yield potential under non-continuously flooded

Table 1. Chemical properties of the soil used in the greenhouse experiment.

\begin{tabular}{|c|c|c|c|c|c|}
\hline $\mathrm{pH}(1: 5)$ in $\left.\mathrm{H}_{2} \mathrm{O}\right)$ & $\begin{array}{c}\text { Organic C (g. } \\
\left.100 \mathrm{~g}^{-1}\right)\end{array}$ & Olsen P (mg.kg ${ }^{-1}$ ) & $\begin{array}{c}\text { Exch. Ca } \\
(\text { meq.100g-1) }\end{array}$ & Exch. K (meq.100g $\mathrm{g}^{-1}$ ) & Total N (g. 100g-1) \\
\hline 6.0 & 1.56 & 39.3 & 15.3 & 0.90 & 0.17 \\
\hline
\end{tabular}


conditions. The seeds were placed on the saturated soil surface on 20 July 2011. Twelve pre-germinated seeds were sown in a single 20 $\mathrm{cm}$ long row along the diameter of each pot. The plants were thinned to eight plants per pot after establishment. The pots were kept weed free by hand weeding as needed.

Insects were well-controlled by applying insecticides as needed against whorl maggot, leaf and plant hoppers, stem borer, and rice bugs.

Air temperature, relative humidity and solar radiation were measured hourly using an automatic weather station in the greenhouse near the middle of the experiment. The same parameters were also measured outdoors at the IRRI lowland farm weather station, located among rice fields about $1 \mathrm{~km}$ from the greenhouse.

All data were analyzed by analysis of variance (ANOVA) using GenStat V.14.1. The interaction between water stress treatment and growth stage was also analyzed using a factorial design with three levels of water stress $(10,20$ and $40 \mathrm{kPa})$ and three stages of stress application (3L - PI, PI - FL, FL - PM). The comparison of treatment means was made by the least significant difference (LSD) at the 5\% level of probability $(\mathrm{p}=0.05)$.

\section{RESULTS AND DISCUSSIONS}

\section{Weather}

Temperature in the greenhouse generally ranged from $30-35^{\circ} \mathrm{C}$, with daily minimum temperature only a couple of degrees lower than maximum temperature (Fig. 1a). Maximum air temperature inside the greenhouse was usually slightly higher than the outside air temperature. However, minimum temperature inside the greenhouse was higher than the outside temperature by several degrees. Relative humidity (\%) in the greenhouse was usually about $10 \%$ lower than that of the outside (Fig. 1b). Solar radiation in the greenhouse was usually much lower inside the greenhouse than that of the outside, by about $50 \%$, except on rainy, overcast days (Fig. 1c). There was strong linear relationship between solar radiation inside and outside the greenhouse (Fig. 1d).

Effect of water stress treatment on the frequency and amount of irrigation

The soil in the water stress treatments dried rapidly after each irrigation (Figs $2 a-c, 3 a-c)$. For example, during 3L-PI, a period of about 42 $\mathrm{d}$, the $10 \mathrm{kPa}$ treatment received 11 irrigations, an average of 1 irrigation every $3.8 \mathrm{~d}$. The frequency of irrigation was only slightly less in the 20 and $40 \mathrm{kPa}$ treatments. The frequency of irrigation within stress treatments was higher during FL-PM than the other two periods, with the $10 \mathrm{kPa}$ receiving an average of one irrigation every $3.3 \mathrm{~d}$.

Fig. 2. Soil water tension in the 10,20 and $40 \mathrm{kPa}$ water stress treatments from three leaf to panicle initiation (a), panicle initiation to flowering and (b) from flowering to physiological maturity in the greenhouse (c) at IRRI, Los Banos, Philippines during July to November 2011. Data are means of four replicates.

Fig. 3. Soil water tension in the 10-10-10 (a), 20-20-20 and (b) 40-40-40 (c) kPa water stress treatments from three leaf to physiological maturity in the greenhouse at IRRI, Los Banos, Philippines during July to November 2011. Data are means of four replicates.

This is consistent with the findings of the field experiments of Sudhir-Yadav et al. (2011) with both puddled transplanted and dry seeded rice on a clay loam soil with a deep water table. They found a large reduction in the number of irrigations in going from $\mathrm{CF}$ to an irrigation threshold of $20 \mathrm{kPa}$, but only small differences in the number/frequency of irrigations as the threshold increased from 20 to 40 to $70 \mathrm{kPa}$. This was partly due to rains, but even in dry spells there were only small delays in drying from 20 to 40 to $70 \mathrm{kPa}$.

During crop establishment, the total number of irrigations and the volume of water added were the same for all the treatments. Imposing water stress at all stages greatly reduced the number of irrigations in comparison with the CF treatment, but the effect on the volume applied 
(a)
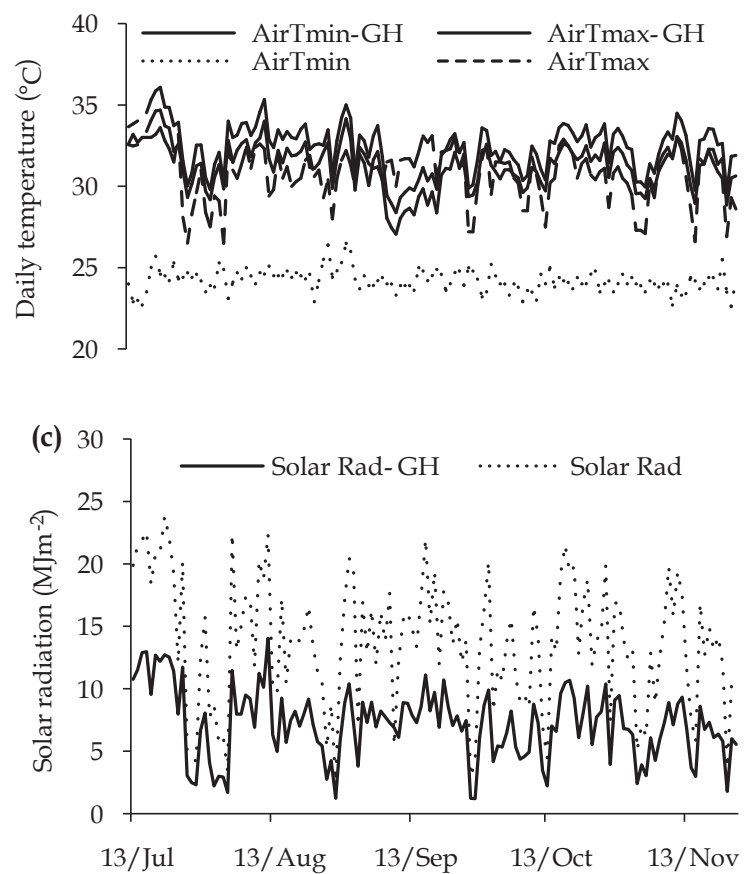

(b)

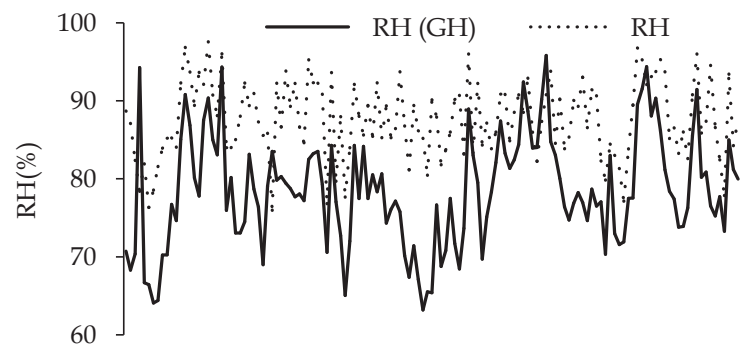

(d)

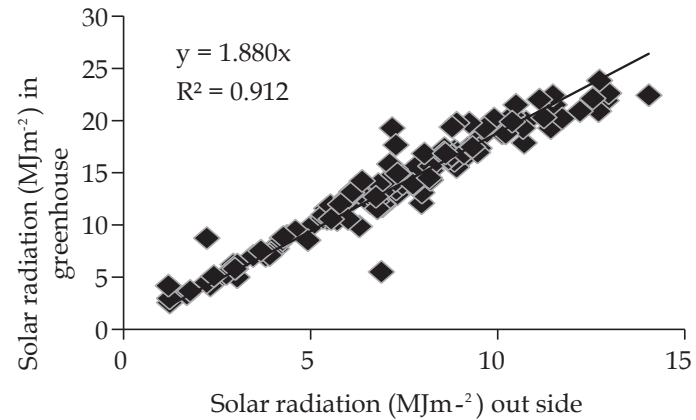

Fig. 1. Daily maximum and minimum temperature (a), daily relative humidity (b), daily solar radiation (c), and the relationship between solar radiation inside and outside the greenhouse (GH) (d) at IRRI, Los Baños, Philippines in 2011.

was negligible (Table 3). During 3L-PI there were small differences between some treatments in the volume applied, but with no meaningful trends. During PI-FL, the treatments with thresholds of 20 and $40 \mathrm{kPa}$ at 3L-PI and/or PIFL received significantly less water than the $\mathrm{CF}$ treatment. During FL-PM, all stress treatments received less water than the CF treatment, regardless of when the stress was applied, except 10-CF-CF. The net result was that total water input to the treatments with 20 or $40 \mathrm{kPa}$ irrigation thresholds at some or all stages was significantly lower (by about 20\%) than input to the CF treatment. There was a consistent trend for higher total water application with a $10 \mathrm{kPa}$ threshold than with higher thresholds, with significantly lower water input in 40-CFCF compared with 10-CF-CF (by 14\%) in CFCF-40 compared with CF-CF-10 (by about 15\%), and in 20-20-20 and 40-40-40 compared with 10-10-10 (by 15-20\%). The effect of the irrigation treatments on irrigation amount was relatively small in comparison with the findings of many field experiments (eg Belder et al., 2004; SudhirYadav et al., 2011). However, the main causes of the irrigation reduction in field experiments were usually reduced seepage and percolation losses (Bouman et al., 2005), whereas, there was no drainage or seepage from the pots. In non-draining pots, irrigation is only needed to replace water lost by evapotranspiration. In treatments with higher irrigation thresholds, the soil dries to a greater degree before irrigation, and therefore a larger amount of water is needed to return the soil to saturation. In nondraining pots differences in irrigation amount thus reflect differences in evaporation and transpiration. The lack of a significant reduction in irrigation input with a threshold of $10 \mathrm{kPa}$ compared with $\mathrm{CF}$ is in contrast with the results of field experiments, which show significant irrigation reduction when changing from $\mathrm{CF}$ to safe AWD (threshold of $\sim 10 \mathrm{kPa}$ ), even for part of the season (Bouman and Tuong, 2001). 

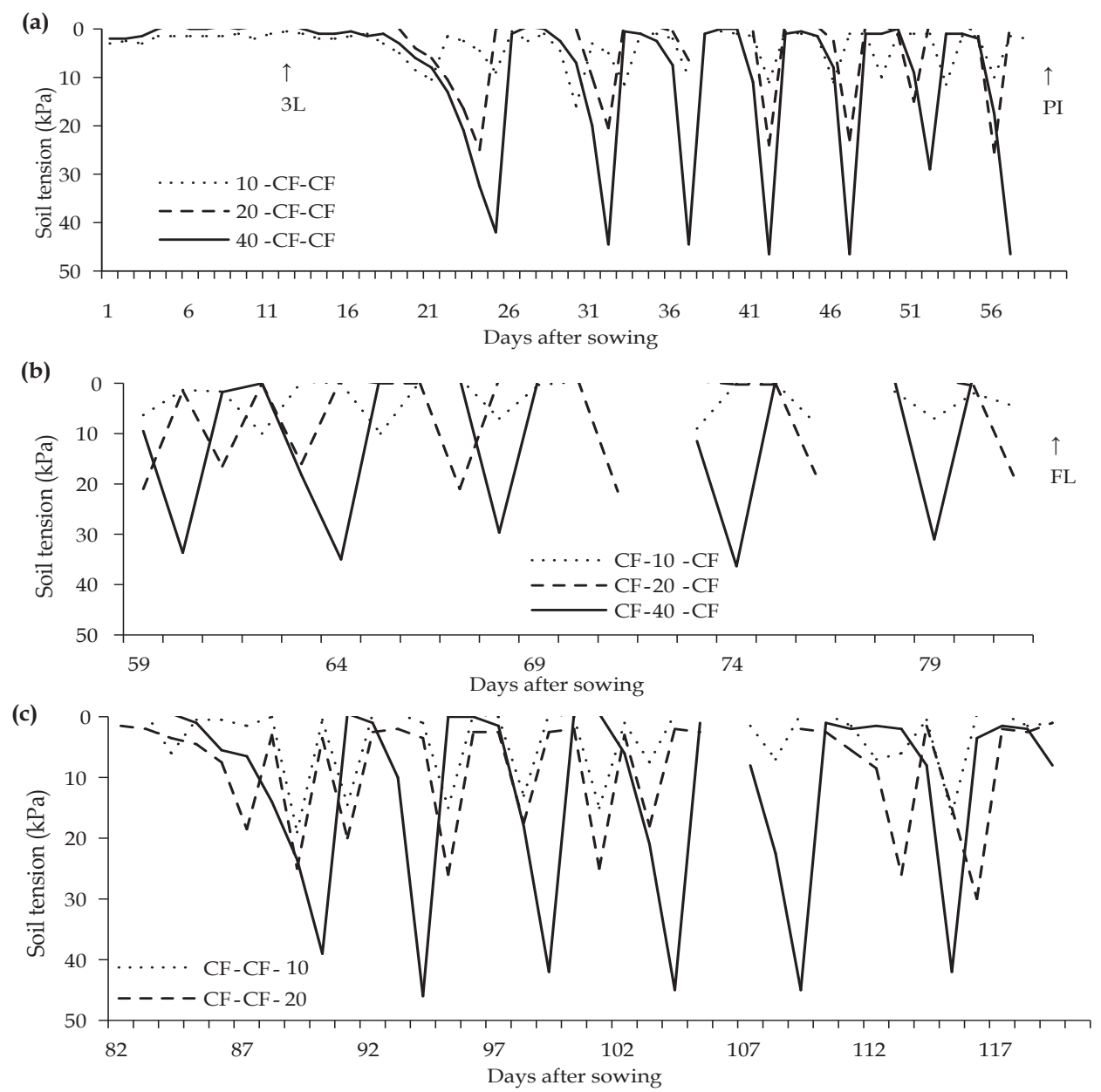

Fig. 2. Soil water tension in the 10,20 and $40 \mathrm{kPa}$ water stress treatments from three leaf to panicle initiation (a), panicle initiation to flowering and (b) from flowering to physiological maturity in the greenhouse (c) at IRRI, Los Banos, Philippines during July to November 2011. Data are means of four replicates.

Effect of water stress treatment on grain yield and yield components

There was a consistent trend for declining grain yield with increasing water stress during all stages, and stresses of 20 and $40 \mathrm{kPa}$ applied during any or all of the three stages significantly reduced yield (Table 4 ). There was a consistent trend for a greater reduction in yield when the stresses of 20 and $40 \mathrm{kPa}$ were applied at all three stages than during a single stage, but the differences were never significant. A stress of $10 \mathrm{kPa}$ did not have a significant effect on yield, except when applied during PI-FL only. The lack of yield reduction with a threshold of
$10 \mathrm{kPa}$ is consistent with the findings of Sharma (1997) in drums in a glasshouse, and of De Datta et al. (1973b) who found only small effects of drying to $10 \mathrm{kPa}$ tension on grain yield, even when the accumulated number of days without water was as many as 38. However, Sharma (1989) found a small (8\%) but significant yield reduction with a threshold of $10 \mathrm{kPa}$ in the field in one of two years. In the present greenhouse experiment, the 10-10-10 treatment received 41 irrigations, meaning that the pots were not ponded for about 41 days (or significant parts thereof). In their review, Bouman and Tuong (2001) reported that yields were reduced by 


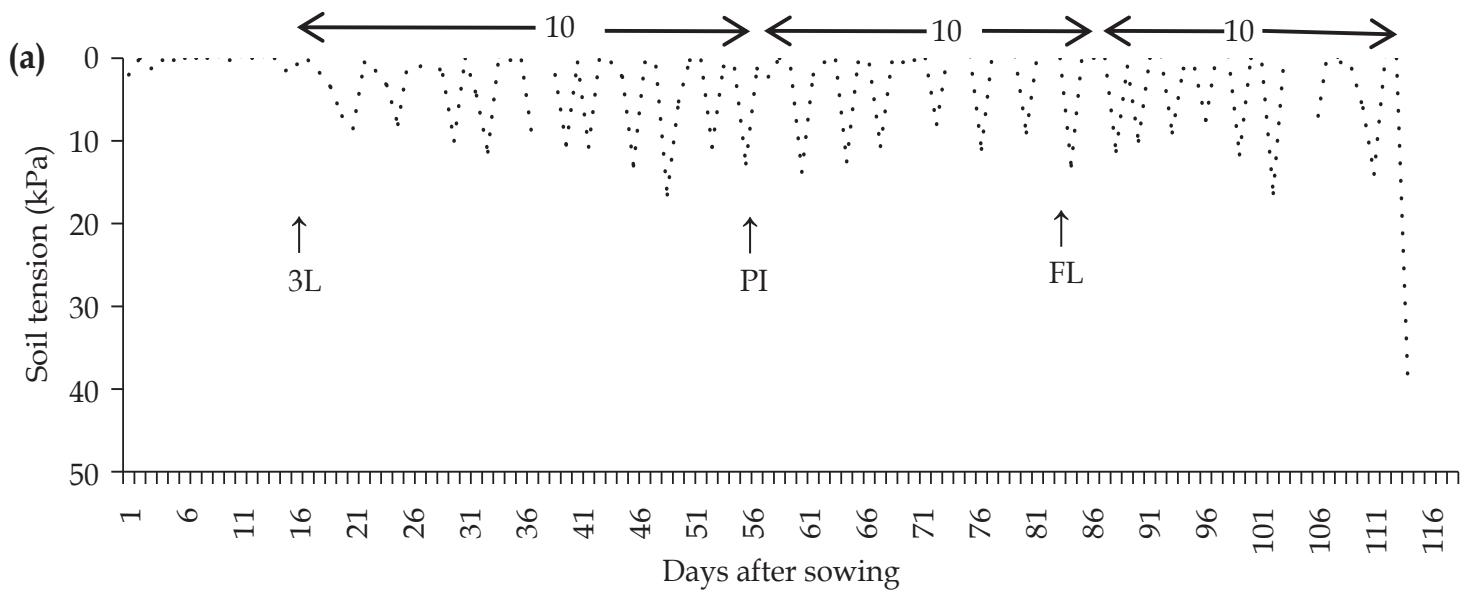

(b)

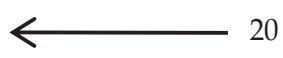

20

20

20

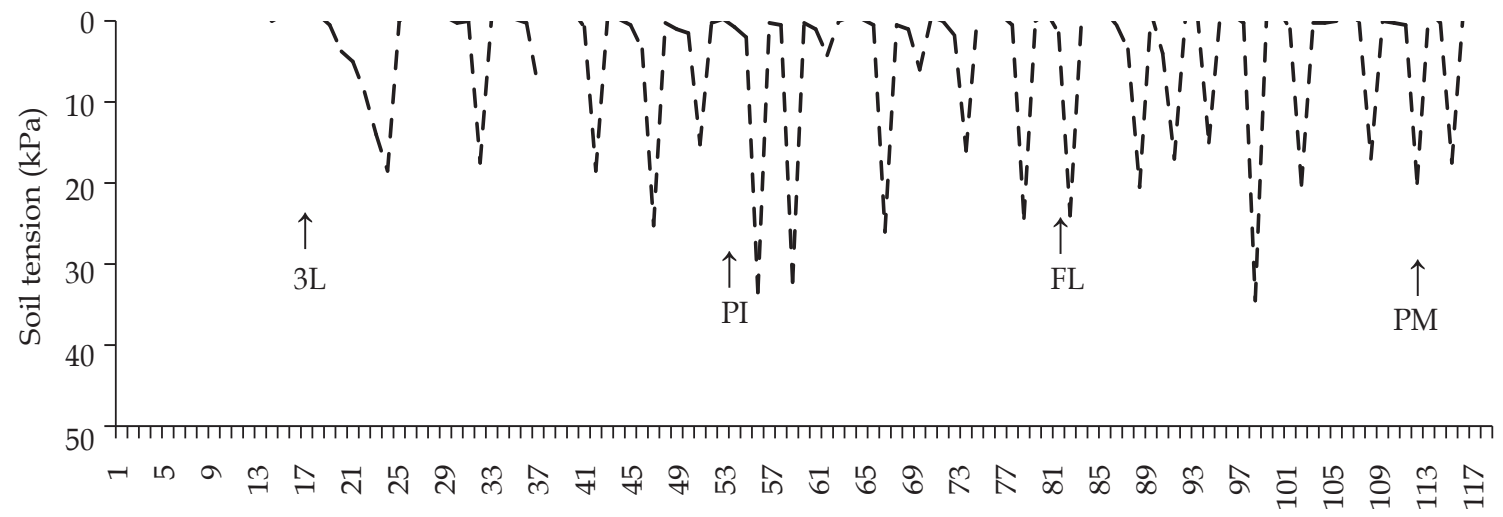

Days after sowing

(c)
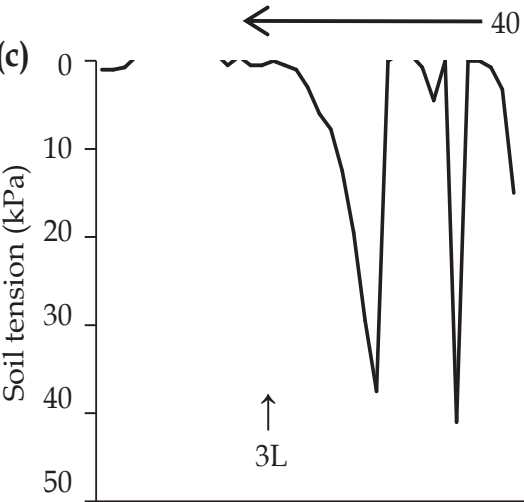

$3 \mathrm{~L}$
40

40
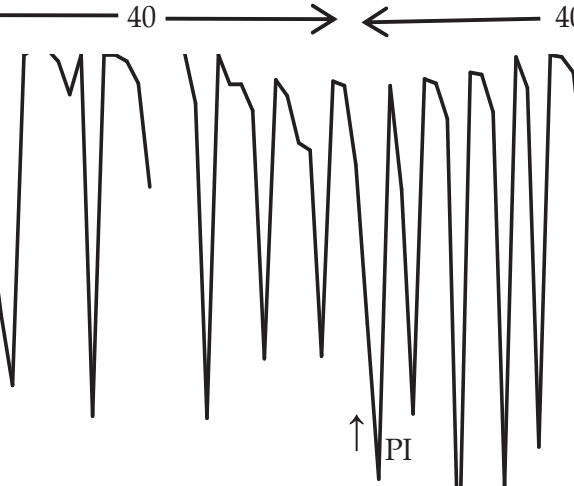

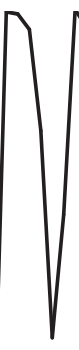

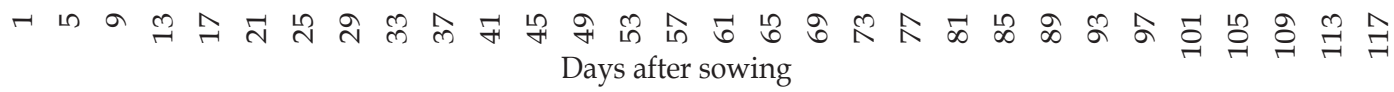

Fig. 3. Soil water tension in the 10-10-10 (a), 20-20-20 (b) and 40-40-40 (c) kPa water stress treatments from three leaf to physiological maturity in the greenhouse at IRRI, Los Banos, Philippines during July to November 2011. Data are means of four replicates. 
Table 3. Effect of irrigation threshold on the number of irrigations (No.) and volume applied during each crop stage and the whole growing season.

\begin{tabular}{|c|c|c|c|c|c|c|c|c|c|c|}
\hline \multirow{2}{*}{ Treatment } & \multicolumn{2}{|c|}{$\begin{array}{c}\text { Crop } \\
\text { establishment }\end{array}$} & \multicolumn{2}{|c|}{ 3L-PI } & \multicolumn{2}{|c|}{ PI-FL } & \multicolumn{2}{|c|}{ FL-PM } & \multicolumn{2}{|c|}{ Whole season } \\
\hline & No. & $\begin{array}{l}\text { Volume } \\
\text { (lit.) }\end{array}$ & No. & $\begin{array}{l}\text { Volume } \\
\text { (lit.) }\end{array}$ & No. & $\begin{array}{l}\text { Volume } \\
\text { (lit.) }\end{array}$ & No. & $\begin{array}{l}\text { Volume } \\
\text { (lit.) }\end{array}$ & No. & $\begin{array}{l}\text { Volume } \\
\text { (lit.) }\end{array}$ \\
\hline $\mathrm{CF}-\mathrm{CF}-\mathrm{CF}$ & 12 & 1.2 & 29.3 & 9.1 & 21.5 & 10.8 & 33.0 & 17.0 & 95.8 & 38.0 \\
\hline 10-CF-CF & 12 & 1.2 & 11 & 9.7 & 18.5 & 9.3 & 31.3 & 15.8 & 72.8 & 36.1 \\
\hline 40-CF-CF & 12 & 1.2 & 8 & 9.0 & 18.0 & 8.1 & 28.3 & 12.6 & 66.3 & 30.9 \\
\hline CF-10-CF & 12 & 1.2 & 32.8 & 9.9 & 10.0 & 10.6 & 31.8 & 11.7 & 87.5 & 33.5 \\
\hline CF-20-CF & 12 & 1.2 & 30.0 & 8.8 & 8.25 & 8.1 & 30.5 & 12.7 & 80.8 & 30.8 \\
\hline CF-40-CF & 12 & 1.2 & 30.3 & 9.1 & 6.0 & 7.3 & 29.5 & 12.9 & 77.8 & 30.6 \\
\hline $10-10-10$ & 12 & 1.2 & 12 & 10.9 & 7 & 9.2 & 10 & 13.7 & 41.0 & 34.9 \\
\hline $20-20-20$ & 12 & 1.2 & 9 & 8.7 & 7 & 8.5 & 8 & 10.1 & 36.0 & 28.6 \\
\hline $40-40-40$ & 12 & 1.2 & 9 & 9.2 & 6 & 8.3 & 8 & 11.2 & 35.0 & 29.8 \\
\hline $\mathrm{LSD}_{0.05}$ & & & 2.32 & 1.63 & 1.9 & 2.1 & 2.55 & 2.09 & 4.8 & 3.9 \\
\hline
\end{tabular}

3L=3 leaf stage, $\mathrm{PI}=$ panicle initiation, $\mathrm{FL}=$ flowering, $\mathrm{PM}=$ physiological maturity, $\mathrm{CF}=$ continuously flooded.

Table 4. Grain yield, yield components, straw yield and harvest index (HI) as affected by water stress imposed at different growth stages compared with continuous flooding.

\begin{tabular}{lccccccc}
\hline Treatment $^{\text {a }}$ & $\begin{array}{c}\text { Pan pot } \\
\text { (no.) }\end{array}$ & $\begin{array}{c}\text { Floret pan }^{-1} \\
\text { (no.) }\end{array}$ & $\begin{array}{c}\text { Floret } \\
\text { fertility }(\%)\end{array}$ & $\begin{array}{c}1000 \text { grain } \\
\text { wt (g) }\end{array}$ & $\begin{array}{c}\text { Grain yield (dry) } \\
\left(\mathrm{g} \mathrm{pot}^{-1}\right)\end{array}$ & $\begin{array}{c}\text { Straw yield } \\
\left.\text { (g pot }^{-1}\right)\end{array}$ & HI \\
\hline CF-CF-CF & 24 & 94 & 86.6 & 21.5 & 41.2 & 50.6 & 0.44 \\
10-CF-CF & 18 & 105 & 90.3 & 21.3 & 34.2 & 48.6 & 0.41 \\
20-CF-CF & 19 & 79 & 86.9 & 21.2 & 27.8 & 43.9 & 0.38 \\
40-CF-CF & 19 & 63 & 86.9 & 21.4 & 21.7 & 44.9 & 0.33 \\
CF-10-CF & 20 & 82 & 85.0 & 21.5 & 30.3 & 45.8 & 0.39 \\
CF-20-CF & 22 & 79 & 85.0 & 20.9 & 27.7 & 41.8 & 0.39 \\
CF-40-CF & 20 & 80 & 77.0 & 21.1 & 25.1 & 42.5 & 0.37 \\
CF-CF-10 & 22 & 97 & 88.5 & 21.7 & 41.7 & 53.2 & 0.43 \\
CF-CF-20 & 20 & 89 & 85.7 & 21.7 & 33.3 & 44.4 & 0.42 \\
CF-CF-40 & 20 & 73 & 83.3 & 20.1 & 24.7 & 41.9 & 0.36 \\
10-10-10 & 19 & 103 & 84.7 & 21.8 & 35.3 & 51.1 & 0.40 \\
20-20-20 & 16 & 91 & 85.0 & 21.4 & 26.4 & 40.1 & 0.39 \\
$40-40-40$ & 14 & 84 & 86.2 & 21.2 & 21.4 & 37.4 & 0.36 \\
LSD 0.05 & 5 & ns & ns & ns & 8.0 & ns & 0.06 \\
\hline
\end{tabular}

a Data were analyzed by RCBD.

8 Parveen et al 
$10-40 \%$ when soil water potentials in the root zone were allowed to reach 10 to $30 \mathrm{kPa}$. A threshold of $40 \mathrm{kPa}$ during a single stage (3LPI, FL-PM) and at all three stages significantly reduced yield by $39-48 \%$ in comparison with the flooded control, and yields with $40 \mathrm{kPa}$ were also lower than yields of all treatments with $10 \mathrm{kPa}$ thresholds at one or all stages, but similar to yields with $20 \mathrm{kPa}$ thresholds. Castillo et al. (2006) found similar yield reductions with severe stress applied during part of the period PI-FL or part of FL-PM. In a field experiment, De Datta et al. (1973b) found 30 and 40\% yield reductions with a $15 \mathrm{kPa}$ threshold for two varieties (IR20 and MI-48), and no further reduction with a threshold of $40 \mathrm{kPa}$.

There was a consistent trend for lower panicle density in all stressed treatments than in $\mathrm{CF}$, with significantly lower values when stresses were applied during the 3L-PI stage or during all the three stages. When the stresses were applied at all stages, panicle density declined as the threshold increased, with significantly lower values in 40-40-40 than 1010-10. Panicle density is determined by both tiller production during the vegetative stage and by tiller mortality after maximum tillering. Sudhir-Yadav et al. (2011) found greater tiller mortality as irrigation threshold increased from daily to 20,40 and $70 \mathrm{kPa}$ following a nonstressed period up to maximum tillering. There was a consistent trend for fewer florets per panicle with 20 and $40 \mathrm{kPa}$ stresses than with $\mathrm{CF}$ during any or all the three stages, but with no significant differences. Floret fertility and 1000 grain weight were not affected by irrigation treatment and there were no consistent trends. Floret fertility is determined during the period of pollen cell formation (a couple of weeks prior to FL) and during anthesis. There were no significant differences in floret fertility, which had a very small range across all treatments (83.3-90.6\%, with $86.6 \%$ in the flooded control) apart from a lower value of $77 \%$ in CF-40-CF. There was also a consistent trend for lower straw yield in all stress treatments (except for $10 \mathrm{kPa}$ during FL-PM), but with no significant differences. There was a strong trend for straw yield to decrease as the stress increased in the treatments stressed during FL-PM or at all stages, but with no significant differences. Harvest index (HI) of all treatments with a $40 \mathrm{kPa}$ threshold at any or all stages was significantly lower than that of the CF treatment. A $20 \mathrm{kPa}$ stress during 3L-PI also resulted in significantly lower HI than the CF treatment.

The factorial analysis showed no significant interactions between irrigation threshold and crop stage during which the irrigation treatment was applied for grain yield and all yield components except grain weight (Tables 5 and 6). Grain yield decreased significantly as the irrigation threshold increased from 10 to 20 to $40 \mathrm{kPa}$. This was largely due to fewer florets per panicle, and to a smaller degree to slightly lower floret fertility (not significant) and grain weight. Grain yield was significantly lower when stresses were applied at 3L-PI or PI-FL than at FL-PM, mainly due to the trend (not significant) for fewer florets per panicle with stresses applied prior to FL. There was significant effect of crop stage on yield and floret fertility (\%).

The lowest average grain weight (20.1 $\mathrm{mg}$ ) was found with a water stress of 40 $\mathrm{kPa}$ during FL-PM only, with significantly lower grain weight than for all other stress $x$ stage combinations (except for a stress of 20 $\mathrm{kPa}$ during PI-FL) (Table 6). Grain weight is influenced by sink size (number of florets. $\mathrm{m}^{-2}$ ) which is determined prior to grain filling, and by the amount of photosynthate available for filling the grains. The photosynthate comes from photosynthate stored in the leaves hence biomass at flowering is an important determinant of grain weight and yield (Yoshida, 1981), and from photosynthesis during the grain filling period (Yoshida, 1981). Assimilates during the grain filling period are mainly translocated to the storage organs (Kropff et al., 1994). There was no correlation between grain weight and any of the water stress indices during grain filling. A stress of $40 \mathrm{kPa}$ during FL-PM resulted in significantly lower grain weight than stresses of 10 and 20 $\mathrm{kPa}$ at the same stage, and than all stresses at 
Table 5. Grain yield, yield components, straw yield and HI as affected by irrigation treatment at different growth stages.

\begin{tabular}{|c|c|c|c|c|c|c|c|c|}
\hline Treatment & $\begin{array}{l}\text { Pan pot }{ }^{-1} \\
\text { (no.) }\end{array}$ & & Floret. pan $^{-1}$ (no.) & $\begin{array}{c}\text { Floret } \\
\text { fertility } \\
(\%)\end{array}$ & $\begin{array}{c}1000 \text { grain } \\
\text { wt }(\mathrm{g})\end{array}$ & $\begin{array}{l}\text { Grain yield } \\
\left(\text { g. } \text { pot }^{-1}\right)\end{array}$ & $\begin{array}{l}\text { Straw yield } \\
\left(\text { g. } \text { pot }^{-1}\right)\end{array}$ & $\mathrm{HI}$ \\
\hline \multicolumn{9}{|c|}{ Water stress $(W, k P a)$} \\
\hline 10 & & 20 & 94.5 & 87.9 & 21.5 & 35.4 & 49.2 & 0.41 \\
\hline 20 & & 21 & 82.4 & 85.9 & 21.2 & 29.6 & 43.4 & 0.40 \\
\hline 40 & & 20 & 72.0 & 82.4 & 20.8 & 23.8 & 43.1 & 0.35 \\
\hline $\mathrm{LSD}_{0.05}$ & & ns & 16.3 & ns & 0.5 & 4.9 & ns & 0.04 \\
\hline \multicolumn{9}{|c|}{ Crop stage $(S)$} \\
\hline $3 L-P I$ & 19 & & 82.1 & 88.0 & 21.3 & 27.9 & 45.8 & 0.37 \\
\hline PI - FL & 21 & & 80.3 & 82.3 & 21.1 & 27.7 & 43.4 & 0.39 \\
\hline FL - PM & 21 & & 86.5 & 85.8 & 21.1 & 33.2 & 46.5 & 0.40 \\
\hline $\mathrm{LSD}_{0.05}$ & ns & & ns & 4.5 & ns & 4.9 & ns & ns \\
\hline \multicolumn{9}{|l|}{$W \times S$} \\
\hline $\mathrm{LSD}_{0.05}$ & ns & & ns & ns & 0.9 & $\mathrm{~ns}$ & ns & ns \\
\hline
\end{tabular}

*Data were analyzed by factorial design. 3L=3 leaf, PI=panicle initiation, FL=flowering, PM=physiological maturity, $\mathrm{CF}=$ continuously flooded.

Table 6. Interaction of water stress and growth stage on 1000 grain weight $(\mathrm{g})$.

\begin{tabular}{lccc}
\hline \multirow{2}{*}{ Treatment } & \multicolumn{3}{c}{ Water stress (W), kPa } \\
\cline { 2 - 4 } & 10 & 20 & 40 \\
\hline Crop stage (S) & & & \\
3L - PI & 21.4 & 21.2 & 21.4 \\
PI - FL & 21.5 & 20.9 & 21.1 \\
FL - PM & 21.7 & 21.7 & 20.1 \\
LSD & & & 0.9 \\
\hline Data were analyzed by factorial design. 3L=3 leaf, & by \\
$\begin{array}{l}\text { PI=panicle initiation, FL=flowering, PM=physiological } \\
\text { maturity, CF=continuously flooded. }\end{array}$
\end{tabular}

the other two stages. Castillo et al. (2006) also found lower grain weight when drought stress was applied during grain filling. However, in the present experiment, when $40 \mathrm{kPa}$ was applied at all three stages, there was no effect on grain weight.

\section{CONCLUSIONS}

With frequent drying, there was no yield reduction for a threshold of $10 \mathrm{kPa}$ applied at
3L-PI or FL-PM, but there was a significant yield decline with $10 \mathrm{kPa}$ applied during PIFL. However, a threshold of $40 \mathrm{kPa}$ reduced yield by $39-47 \%$ when applied at a single stage (3L-PI, PI-FL, FL-PM), while a threshold of 20 $\mathrm{kPa}$ reduced yield by $19-33 \%$ when applied at a single stage. There was a slightly greater yield reduction (36-48\%) when stresses of 20 and $40 \mathrm{kPa}$ were applied throughout all the three stages compared with at a single stage. Once the soil starts drying, soil tension increases rapidly from 10 to $40 \mathrm{kPa}$, as evidenced by only a very small difference in the number of irrigations applied to each stress treatment within each stage.

\section{RECOMMENDATIONS}

The degree of soil drying and the number of drying events are important determinants of crop response to soil drying, and this needs to be considered in setting the irrigation threshold for safe AWD (no yield loss). Given the high sensitivity of rice to water deficit stress as the 
soil dries beyond $10 \mathrm{kPa}$, and the fact that there are only small additional water savings in increasing the irrigation threshold above $10 \mathrm{kPa}$, it is better to adopt conservative AWD practices ie using a threshold of $10 \mathrm{kPa}$ during the vegetative and grain filling stages, and to keep the soil close to saturation during PI-FL.

\section{ACKNOWLEDGEMENTS}

The authors sincerely express their gratitude to the authority of International Rice Research Institute, Los Banos, Philippines for offering the fellowship (2009 Global Rice Science Scholarship) and providing necessary assistance in this regard. The financial support of Cereal Systems Initiative for South Asia (CSISA), Bill and Melinda Gates Foundation and USAID is gratefully acknowledged. The authors are also grateful to the scientists and staffs of Water Science Group of CESD, IRRI, Philippines for their help during the experiment particularly to Dr Olivyn Angeles and Dr Romeo Cabangon.

\section{REFERENCES}

Belder, P, B A M Bouman, R Cabangon, L Guoan, E J P Quitang, L Yuanhua, J H J Spiertz and T P Tuong. 2004. Effect of water-saving irrigation on rice yield and water use in typical lowland conditions in Asia. Agric. Water Manag. 65: 193-210.

Bouman, B A M and T P Tuong. 2001. Field water management to save water and increase its productivity in irrigated rice. Agric. Water Manage, 49: 11-30.

Bouman, B A M, S Peng, A R Castañeda and R M Visperas. 2005. Yield and water use of irrigated tropical aerobic rice systems. Agric. Water Manage. 74: 87-105.

Bueno, C S, M Bucourt, N Kobayashi, K Inubushi and T Lafarge. 2010. Water productivity of contrasting rice genotypes grown under water-saving conditions in the tropics and investigation of morphological traits for adaptation. Agricultural Water management 98(2): 241-250.

Cabangon, R J, T P Tuong and N B Abdullah. 2002. Comparing water input and water productivity of transplanted and direct-seeded rice production systems. Agric. Water Manage. 57: 11-31.
Castillo, E G, T P Tuong, U Singh, K Inubushi and J Padilla. 2006. Drought response of dry-seeded rice to water stress timing and N-fertilizer rates and sources. Soil Science and Plant Nutrition 52: 496-508.

Davatgar, N, M R Neishabouri, A R Sepaskhah and A Soltani. 2009. Physiological and morphological responses of rice (Oryza sativa L.) to varying water stress management strategies. International Journal of Plant Production 3(4) October 2009.

De Datta, S K, H K Krupp, E I Alvarez and S C Modgal. 1973. Water management practices in flooded tropical rice. In: Water Management in Philippines Irrigation Systems: Research and Operations. International Rice Research Institute, Los Banos, Philippines, pp. 1-18.

De Datta, S K, H K Krupp, E I Alvarez and S C Modgal. 1973b. Water management practices in flooded tropical rice. Water management in Philippine irrigation systems: Research and operations: Papers presented at the Water Management Workshop, December 11-14, 1972, International Rice Research Institute, Los Baños (1973), pp. 1-18.

De Datta, S K, W P Abilay, G N Kalwar. 1973a. Water stress effects in flooded tropical rice. Water management in Philippine irrigation systems: Research and operations: Papers presented at the Water Management Workshop, December 11-14, 1972, International Rice Research Institute, Los Baños, pp. 19-36.

Guerra, L C, S I Bhuiyan, T P Tuong and R Barker. 1998. Producing More Rice with Less Water from Irrigated Systems. SWIM Paper 5. IWM/IRRI, Colombo, Sri Lanka, 24pp.

Humphreys, E, S S Kukal, E W Christen, Balwinder-singh, Sudhir-Yadev and R K Sharma. 2010. Halting the groundwater decline in North West India- Which crop technologies will be winners? Advanced Agronomy. 109: 155-217.

Kropff, M J, H H van Laar and R Mathews. 1994. ORYZA1, an ecophysiological model for irrigated rice production. In: SARP Research Proceedings. IRRI/AB-DLO, Wageningen, the Netherlands, 110pp.

Kukal, SS, GS Hira and A S Sidhu. 2005. Soil metric potentialbased irrigation scheduling to rice (Oryza sativa). Irrig. Sci., 23: 153-159.

Kumar, V and J K Ladha. 2011. Direct Seeding of Rice: Recent Development and Future Research Needs. International Rice Research Institute, India office, Pusa, New Delhi, India.

Rashid, M H, M M Alam, M A H Khan and J K Ladha. 2009. Productivity and resource use of direct-(drum)-seeded 
and transplanted rice in puddle soils in rice-rice and rice-wheat ecosystems. Field Crops Research 113 274-281.

Sharma, P K. 1989. Effect of periodic moisture stress on water-use efficiency in wetland rice. Oryza 26: 252257.

Sharma, A R. 1997. Effect of integrated weed management and nitrogen fertilization on the performance of rice under flood-prone lowland conditions. J. Agric. Sci. Cambridge 129: 409-418.

Sudhir-Yadev, E Humphreys, S S Kukal, G Gill and R Ranaranjan. 2011. Effect of water management on dry seeded and puddle transplanted rice Part 2: Water balance and water productivity. Field Crops Research 120: 123-132.

Wopereis, M C S, M J Kropff, A R Maligaya and T P Tuong. 1996. Drought-stress responses of two lowland rice cultivars to soil water status. Field Crops Research, 46: 21-39.

Yoshida, S. 1981. Fundamentals of rice crop science, 269 pp. International Rice Research Institute, Los Banos, Philippines. 